\title{
Hydrogen Effect against Hydrogen Embrittlement
}

\author{
YUKITAKA MURAKAMI, TOSHIHIKO KANEZAKI, and YOJI MINE
}

\begin{abstract}
The well-known term "hydrogen embrittlement" (HE) expresses undesirable effects due to hydrogen such as loss of ductility, decreased fracture toughness, and degradation of fatigue properties of metals. However, this article shows, surprisingly, that hydrogen can have an effect against HE. A dramatic phenomenon was found in which charging a supersaturated level of hydrogen into specimens of austenitic stainless steels of types 304 and 316L drastically improved the fatigue crack growth resistance, rather than accelerating fatigue crack growth rates. Although this mysterious phenomenon has not previously been observed in the history of HE research, its mechanism can be understood as an interaction between hydrogen and dislocations. Hydrogen can play two roles in terms of dislocation mobility: pinning (or dragging) and enhancement of mobility. Competition between these two roles determines whether the resulting phenomenon is damaging or, unexpectedly, desirable. This finding will, not only be the crucial key factor to elucidate the mechanism of HE, but also be a trigger to review all existing theories on HE in which hydrogen is regarded as a dangerous culprit.
\end{abstract}

DOI: $10.1007 / \mathrm{s} 11661-010-0275-6$

(C) The Author(s) 2010. This article is published with open access at Springerlink.com

\section{INTRODUCTION}

DURING the past 40 to 50 years, many articles ${ }^{[1-7]}$ on hydrogen embrittlement (HE) have been published, and several hypotheses have been proposed. From a macroscopic viewpoint, most research showed undesirable effects in the deterioration in strength properties caused by hydrogen. Among deleterious effects of hydrogen, ductility $\operatorname{loss}^{[8-10]}$ is a well-known phenomenon. Hydrogen-induced degradation in fracture toughness, ${ }^{[11-13]}$ fatigue strength, and fatigue crack growth properties ${ }^{[14-20]}$ has also caused concern in various industrial sectors. With respect to the relationship between hydrogen and microstructure, localized plasticity due to hydrogen-enhanced dislocation mobility ${ }^{[3-5,21-26]}$ and crystallographic slip localization by hydrogen ${ }^{[27-29]}$ have also attracted considerable attention in the field of materials science. It is pertinent to regard the interaction between hydrogen and dislocations as being strongly correlated with microscopic plastic deformation behavior in almost all metallic materials, and also with straininduced martensitic transformation in austenitic steels. $^{[30-32]}$ Birnbaum and co-workers ${ }^{[22-24]}$ found that hydrogen decreased the microscopic yield stress; this

YUKITAKA MURAKAMI, Trustee, Department of Mechanical Engineering, Kyushu University, Fukuoka 819-0395, Japan, is Director, Research Center for Hydrogen Industrial Use and Storage (HYDROGENIUS), National Institute of Advanced Industrial Science and Technology (AIST), Fukuoka 819-0395, Japan. Contact e-mail: ymura@mech.kyushu-u.ac.jp TOSHIHIKO KANEZAKI, formerly Research Associate Professor, Department of Mechanical Engineering, Kyushu University, is with the Automobile R\&D Center, Honda R\&D Co., Ltd. YOJI MINE, Assistant Professor, Department of Mechanical Engineering, Kyushu University, is with the Research Center for Hydrogen Industrial Use and Storage (HYDROGENIUS), National Institute of Advanced Industrial Science and Technology (AIST), Fukuoka 819-0395, Japan.

Manuscript submitted October 7, 2009.

Article published online June 22, 2010 finding was based on in-situ transmission electron microscopy (TEM) observation of increased dislocation movement caused by hydrogen. However, hydrogen effects are not necessarily limited to the enhancement of dislocation mobility, namely, to assisting crystallographic glide. There are more articles that report increased macroscopic yield strength of austenitic stainless steels due to hydrogen ${ }^{[27,33-35]}$ than those that report decreased yield strength. The precise studies by Kirchheim and co-workers ${ }^{[36,37]}$ showed that hydrogen has two contradictory effects, i.e., both resisting and enhancing dislocation motion. Gavriljuk and co-workers ${ }^{[38,39]}$ report hydrogen-induced softening of austenitic steels, as revealed by internal friction measurement, whereas tensile tests showed hardening in hydrogen-charged specimens. Birnbaum and Sofronis ${ }^{[5]}$ attempted to resolve the contradictory hydrogen effects, especially the decrease in "microscopic" flow stress (softening) vs the increase in "macroscopic" flow stress (hardening); they used a combination of TEM experiments and theoretical analysis of hydrogen-dislocation interaction. An increase in macroscopic flow stress, i.e., hardening, due to hydrogen charging has been observed by many researchers, while there are fewer reports of decreased macroscopic flow stress, i.e., softening, due to hydrogen. ${ }^{[40,41]}$

Internal friction measurements to characterize the deformation resistance of materials have been used by many researchers in order to investigate the interaction between hydrogen and dislocation movement in hydrogen-charged specimens. On the other hand, observing the effect of hydrogen on fatigue crack growth behavior enables one to elucidate the slip band formation morphology in the vicinity of a crack tip (e.g., Murakami,${ }^{[42]}$ Uyama et al..${ }^{[43]}$ Murakami et al.,${ }^{[4]}$ and Kanezaki et al. ${ }^{[45]}$, and also to reveal evidence of dislocation movement in plastically deformed grains. Unlike the traditional methods, e.g., tensile testing, 
observing the microscopic aspects of fatigue crack growth behavior is expected to provide a possibility of resolving the HE mechanism problem from a fresh point of view. However, precise experimental techniques are needed.

Uyama et al. ${ }^{[43]}$ studied statistical aspects of slip band morphology in ferrite grains in both hydrogen-charged and uncharged specimens of medium carbon steels, tested by fatigue loading, and quantitatively identified the effect of hydrogen on crystallographic slip. Uncharged specimens containing $\sim 0 \mathrm{wt}$ ppm hydrogen had slip bands that totally covered each ferrite grain, with either cross-slip or parallel slip. On the other hand, in hydrogen-charged specimens containing 0.2 to $0.8 \mathrm{wt}$ ppm hydrogen, 50 pct of the ferrite grains were covered with discrete slip bands in a zebra pattern. Most fatigue cracks were nucleated along grain boundaries in uncharged specimens, while in hydrogen-charged specimens, the proportion of cracks generated along slip bands reached approximately $20 \mathrm{pct}$, and the total density of crack initiation was higher than in uncharged specimens. Another interesting phenomenon to be noted is the difference in cyclic stress-strain hysteresis loops between hydrogen-charged specimens and uncharged specimens. Stress-strain hysteresis loops obtained in stress-controlled cyclic tensile-compression tests exhibited a narrower strain range, $\Delta \varepsilon$, in hydrogen-charged specimens than in uncharged specimens. This indicates that macroscopic hardening (increase of flow stress) occurred in the presence of hydrogen, and that this can be correlated with the zebra pattern of slip bands in deformed ferrite grains. Consequently, the phenomenon indicated by Uyama et al. ${ }^{[43]}$ implies that at least some strength properties, such as the cyclic stress-strain hysteresis loop, may be improved by hydrogen charging.

Murakami et al. ${ }^{[44]}$ and Kanezaki et al. ${ }^{[45]}$ investigated the fatigue crack behavior of hydrogen-charged and uncharged specimens of types 304 and 316L austenitic stainless steels. They found a strange phenomenon in the relationship between slip morphology and fatigue crack growth rate. In the uncharged specimens, many grains were covered with slip bands around a fatigue crack, while in the hydrogen-charged specimens, slip bands appeared only in the vicinity of a crack, but under the same stress, fewer slip bands were observed in grains away from the crack. This phenomenon shows that hydrogen increased the resistance against crystallographic glide, i.e., hydrogen hindered dislocation motion, eventually leading to hardening. Nevertheless, fatigue crack growth rates for the hydrogen-charged specimens were significantly increased compared with those for uncharged specimens.

What does this contradiction in the results of optical microscopic observations mean? Hydrogen increases macroscopic strength by slip localization, resulting in a discrete slip band arrangement, so why are fatigue crack growth rates accelerated in the presence of hydrogen? One possible interpretation is that the phenomenon that occurs at the fatigue crack tip differs from slip behavior in grains away from the crack. However, as shown in the detailed observations by Murakami et al. ${ }^{[4]}$ and Kanezaki et al.., ${ }^{[4]}$ it is evident that the deformation process at a fatigue crack tip in austenitic stainless steels is based on crystallographic slip, and the fatigue crack growth is not based on a decohesion mechanism. It was shown ${ }^{[20,44]}$ that the fracture mechanism at a fatigue crack tip is essentially a ductile microfracture, since clear striations were observed on the fracture surfaces of hydrogen-charged specimens. The lattice decohesion model $^{[1,2]}$ cannot be related to this phenomenon. The basic mechanism of the fracture process at a fatigue crack tip is slip originated by dislocation motion in crystals. Therefore, we need to recognize that the source of the mystery exists in the interaction between hydrogen and dislocations. A similar phenomenon has also been observed in a bcc metal. ${ }^{[19]}$ The objective of the present article is to resolve the mystery of HE through a detailed observation of the slip band morphologies, and the fatigue crack growth behavior, of hydrogen-charged types 304 and $316 \mathrm{~L}$.

In order to achieve this objective, we paid particular attention to the quantitative effects of hydrogen content, ranging from an uncharged level to supersaturated levels in the material. From the term "hydrogen embrittlement," we presume that the higher the hydrogen content in a material, the lower the strength properties of the material. Indeed, Murakami et al. ${ }^{[4]}$ showed that when 2 to $3 \mathrm{wt} \mathrm{ppm}$ nondiffusible hydrogen in uncharged solution-treated austenitic stainless steels was removed by a special heat treatment, the fatigue crack growth properties were remarkably improved.

In this study, a uniform high hydrogen content distribution throughout fatigue specimens was obtained by exposing types 304 and 316L specimens to gaseous hydrogen at a pressure up to approximately $100 \mathrm{MPa}$ and at a temperature of $553 \mathrm{~K}\left(280^{\circ} \mathrm{C}\right)$. It must be noted that the hydrogen content of specimens obtained by this hydrogen charging method is much higher than the thermal equilibrium hydrogen content for the atmospheric pressure and ambient temperature, under which fatigue testing was carried out. The effect of hydrogen content on crystallographic slip, i.e., the interaction between hydrogen and dislocations, can be visualized by room-temperature fatigue tests on specimens with different hydrogen contents. In tests on specimens containing supersaturated hydrogen, the authors anticipated the appearance of strong HE, but what actually happened was surprising and dramatic. The unexpected experimental results obtained will be presented in this article, and thereby the microscopic mechanism of HE will be revealed.

Before discussing the main subject, we briefly review suitable methods for investigating the effect of hydrogen on mechanical properties of materials. The results obtained by conventional experimental methods and their advantages and disadvantages are summarized as follows.

(1) Internal friction measurement on hydrogen-precharged specimens: Measurement of internal friction, i.e., the interaction between hydrogen and dislocations. The results cannot be linked directly to fracture phenomena.

(2) Tensile testing of hydrogen-precharged specimens: Measurement of macroscopic ductility loss 
(reduction of area) in the presence of hydrogen and the effect of hydrogen on stress-strain curve (softening or hardening). The hydrogen content in a specimen can be quantified.

(3) Tensile testing during electrochemical hydrogen charging: Measurement of the effect of hydrogen on stress-strain curves (softening or hardening). Difficult to identify the effect of the hydrogen content gradient from a specimen surface to the subsurface. Difficult to avoid surface effects. ${ }^{[40,41]}$

(4) Tensile testing in a hydrogen gas environment: Measurement of the macroscopic ductility loss caused by environmental gaseous hydrogen. Difficult to identify the effect of the hydrogen content gradient from the surface to the subsurface in a specimen. Difficult to avoid surface effects. ${ }^{[40,41]}$ Difficult to identify the hydrogen content in a specimen.

(5) Fatigue testing of hydrogen-precharged specimens: Possible to identify the effects of hydrogen on slip band formation and on fatigue crack initiation and growth. Fracture surface features, e.g., striations (failure mechanism), can be examined. The hydrogen content in a specimen can be quantified. There are three types of hydrogen charging method. To avoid damage and cracking on the specimen surface, hydrogen charging under high-pressure gaseous hydrogen is desirable.

(6) Fatigue testing in hydrogen gas environment: Possible to identify the effects of hydrogen on slip band formation and on fatigue crack initiation and growth. Difficult to quantify the hydrogen content in a specimen.

(7) Fracture toughness testing in hydrogen gas environment: Possible to identify the effect of hydrogen on static unstable crack growth processes. Difficult to quantify the hydrogen content in a specimen.

(8) Fracture toughness testing during electrochemical hydrogen charging: Possible to identify the effect of hydrogen on static unstable crack growth processes. Difficult to quantify the hydrogen content in a specimen. Difficult to separate the effect of corrosion (chemical reaction) from a pure hydrogen effect.

\section{MATERIALS AND EXPERIMENTAL METHODS}

\section{A. Materials and Specimens}

The materials used in this study are round bars of two types of austenitic stainless steel (type 304 stainless steel and type $316 \mathrm{~L}$ stainless steel). Table I shows the chemical compositions. Table II shows the tensile properties and Vickers hardness (load: $9.8 \mathrm{~N}$ ) of these materials. Round bars of types 304 and $316 \mathrm{~L}$ were solution heat treated. Solution heat treatment was carried out by water quenching after soaking at $1323 \mathrm{~K}\left(1050{ }^{\circ} \mathrm{C}\right)$ for 2 minutes for type 304 and for 10 minutes for type $316 \mathrm{~L}$. The hydrogen contents of the solution-treated specimens are $2.2 \mathrm{wt}$ ppm for type 304 and $2.6 \mathrm{wt} \mathrm{ppm}$ for type $316 \mathrm{~L}$. Hydrogen contents were measured by thermal desorption spectrometry (TDS) using a quadruple mass spectrometer. The measurement accuracy of the TDS is $0.01 \mathrm{wt} \mathrm{ppm}$. Measurements were carried out up to $1073 \mathrm{~K}\left(800{ }^{\circ} \mathrm{C}\right)$ at a heating rate of $0.5 \mathrm{~K} / \mathrm{s}$.

Figures 1(a) and (b) show the fatigue specimen dimensions and the small hole that was introduced into each specimen surface. After polishing with \#2000 emery paper, specimen surfaces were finished by buffing using colloidal $\mathrm{SiO}_{2}(0.04 \mu \mathrm{m})$ solution. A small artificial hole, $100-\mu \mathrm{m}$ diameter and $100-\mu \mathrm{m}$ deep, was then drilled into each specimen surface as a fatigue crack growth starter. In the hydrogen-charged specimens, the hole was introduced immediately after hydrogen charging.

The amount of martensite at the specimen surfaces of austenitic steel specimens was measured by the X-ray diffraction method, using monochromatic $\mathrm{Cr} K_{\alpha}$ radiation. The martensite content was evaluated by the ratio of the integrated intensity of the $\{220\}$ austenite peak and the $\{211\}$ martensite peak. The amount of martensite before fatigue testing in the types 304 and 316L specimens was, at most, approximately 3 pct. It should be noted that the amount of martensite measured by the X-ray diffraction method also includes the amount of $\delta$-ferrite.

Table I. Chemical Compositions (Weight Percent, *Weight Parts per Million)

\begin{tabular}{lccccccccc}
\hline Type & $\mathrm{C}$ & $\mathrm{Si}$ & $\mathrm{Mn}$ & $\mathrm{P}$ & $\mathrm{S}$ & $\mathrm{Ni}$ & $\mathrm{Cr}$ & $\mathrm{Mo}$ & $\mathrm{H}^{*}$ \\
\hline 304 & 0.06 & 0.36 & 1.09 & 0.030 & 0.023 & 8.19 & 18.66 & - \\
$316 \mathrm{~L}$ & 0.019 & 0.78 & 1.40 & 0.037 & 0.010 & 12.08 & 17.00 & 2.04 \\
$316 \mathrm{~L}^{\dagger}$ & 0.010 & 0.53 & 0.77 & 0.023 & 0.001 & 12.13 & 17.16 & 2.86 & 1.5 \\
\hline
\end{tabular}

$\mathrm{H}^{*}$ is equivalent to the notation $C_{\mathrm{H}}$ used in the text.

Table II. Tensile Properties and Vickers Hardness $H V$

\begin{tabular}{lccccc}
\hline \multicolumn{4}{c}{ Tensile Properties } & & \\
\cline { 2 - 5 } Type & 0.2 Pct Proof Stress $\sigma_{0.2}(\mathrm{MPa})$ & Tensile Strength $\sigma_{B}(\mathrm{MPa})$ & Elongation $\varepsilon_{f}$ & Reduction of Area $\varphi$ & Hardness HV \\
\hline 304 & 309 & 713 & 0.74 & 0.82 & 176 \\
$316 \mathrm{~L}$ & 319 & 627 & 0.74 & 0.78 & 157 \\
\hline
\end{tabular}




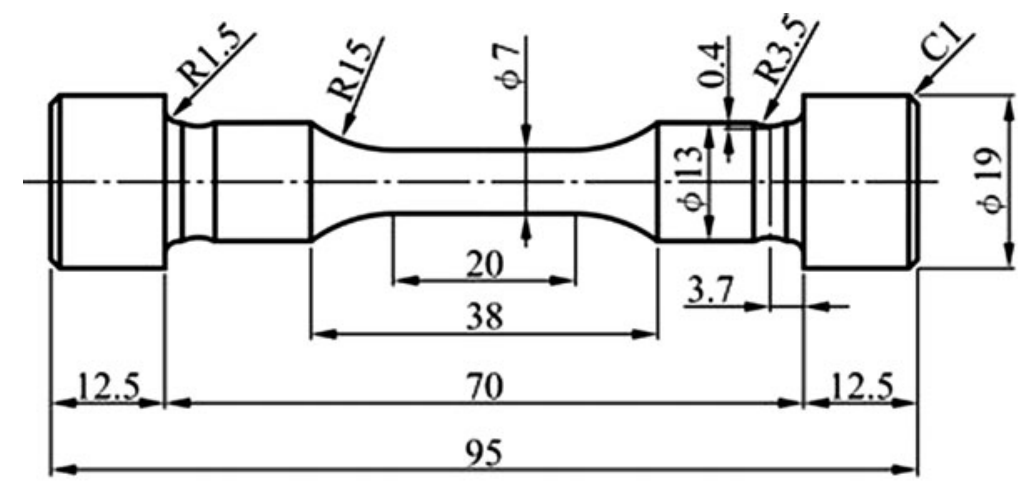

(a)

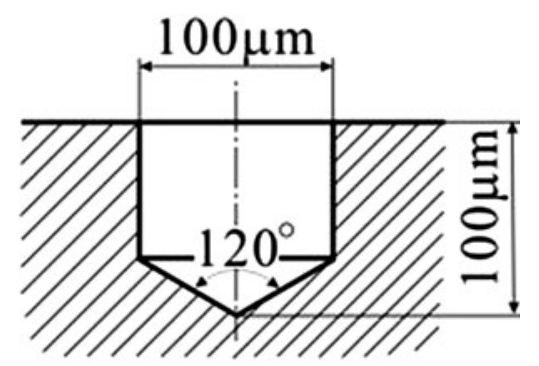

(b)

Fig. 1-Dimensions of (a) fatigue test specimen and $(b)$ drilled hole.

Table III. Relationship between Hydrogen Content and Hydrogen Charge Condition

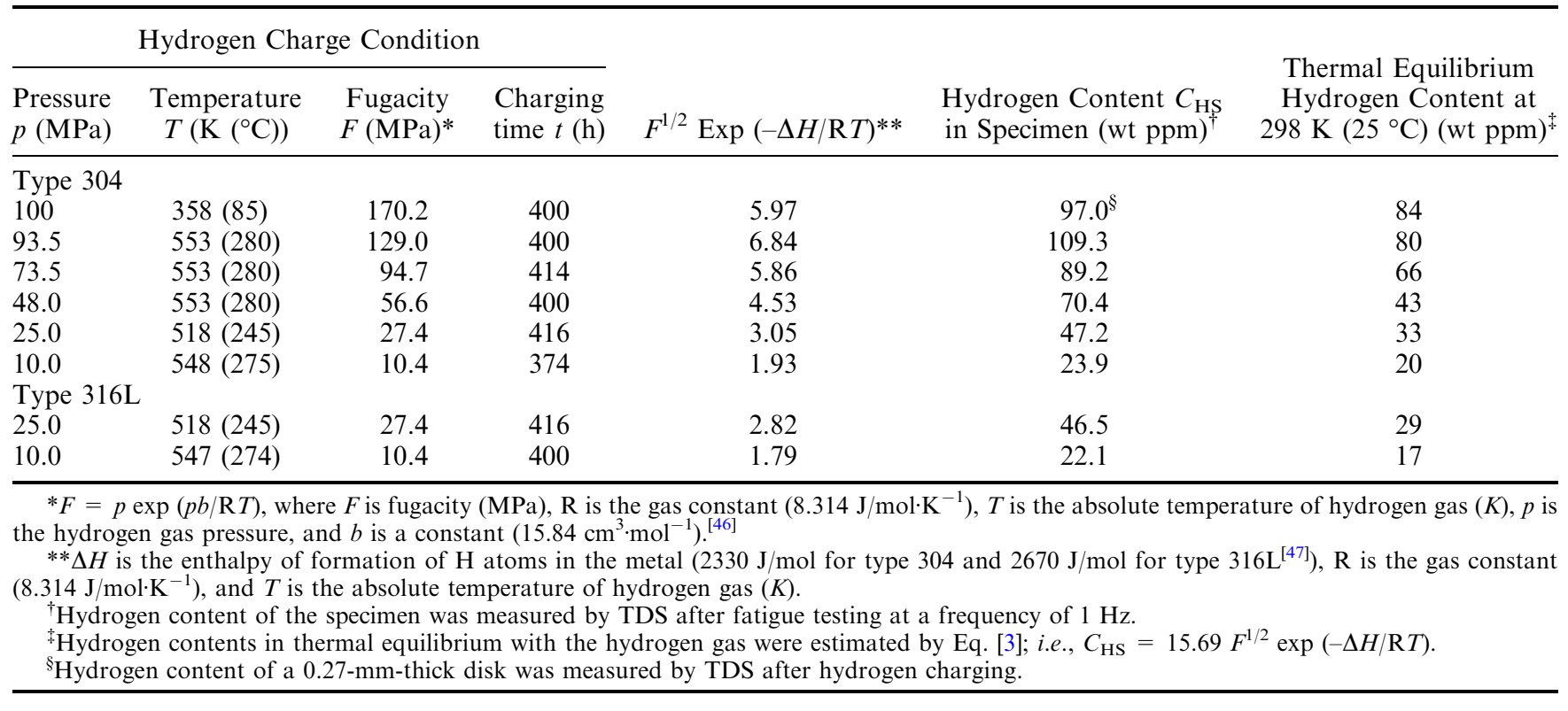

\section{B. Hydrogen Charging Method and Hydrogen Entry Property}

Hydrogen was charged into fatigue specimens by exposure to high-pressure hydrogen gas. The charging time was determined by estimating the condition for saturation of hydrogen in a 7-mm-diameter round bar fatigue specimen. Table III shows the relationship between the hydrogen charging conditions and the hydrogen content. The content of hydrogen charged at high pressure is denoted "supersaturated" in ambient temperature fatigue tests. The hydrogen content of a specimen was measured by TDS after each fatigue test; a 0.8 -mm-thick disk for TDS measurement was cut from the specimen, under water cooling, immediately after the test. It has been confirmed that the process of cutting disks from a specimen does not affect the hydrogen content of a disk sample. ${ }^{[4]}$ Hydrogen release from specimens during fatigue tests ( $<600$ hours) is considered to be negligibly small because hydrogen diffusion in austenitic stainless steels is very slow at room temperature. Therefore, the saturated hydrogen content may be evaluated by the hydrogen content after a fatigue test.

San Marchi et al. ${ }^{[46]}$ present the following equations, which express the content of hydrogen that is dissolved in the metal lattice and is in equilibrium with the hydrogen gas.

$$
\begin{gathered}
C_{\mathrm{HS}}=\alpha \sqrt{F} \exp \left(\frac{-\Delta H}{\mathrm{R} T}\right) \\
F=p \exp \left(\frac{p b}{\mathrm{R} T}\right)
\end{gathered}
$$

where $\alpha$ is a constant, $F$ is fugacity (MPa), R is the gas constant $(8.314 \mathrm{~J} / \mathrm{mol} \cdot \mathrm{K}),(\Delta H$ is the enthalpy of formation of $\mathrm{H}$ atoms in the metal $(2330 \mathrm{~J} / \mathrm{mol} \cdot \mathrm{K}$ for type 304 and $2670 \mathrm{~J} / \mathrm{mol} \cdot \mathrm{K}$ for type $316 \mathrm{~L}^{[47]}$ ), $T$ is the absolute temperature of the hydrogen gas $(K)$, $p$ is the hydrogen gas pressure, and $b$ is a constant 


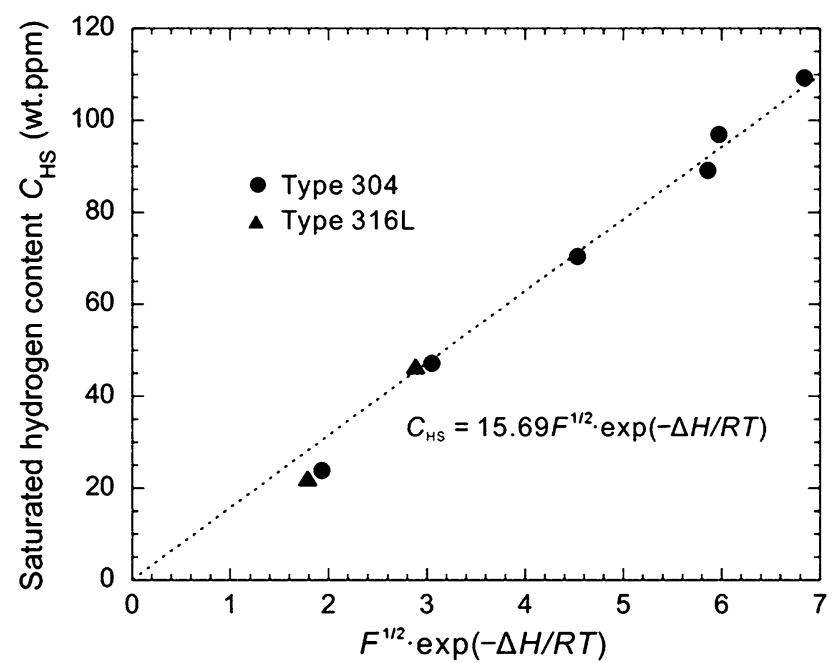

Fig. 2-Relationship between hydrogen content and hydrogen charge condition.

$\left(15.84 \mathrm{~cm}^{3} / \mathrm{mol}^{[46]}\right)$. Sieverts' law is a special case of chemical equilibrium for reaction in the limit of ideal gas behavior (fugacity $F \rightarrow$ pressure $p$ ). Figure 2 shows the experimental relationship between the hydrogen charge condition and the hydrogen content. From the figure, the saturated hydrogen content in equilibrium with the hydrogen gas is given by the following equation:

$$
C_{\mathrm{HS}}=15.69 \sqrt{F} \exp \left(\frac{-\Delta H}{\mathrm{R} T}\right)
$$

The values of saturated hydrogen contents evaluated by Eq. [3] for room temperature $\left(298 \mathrm{~K}\left(25^{\circ} \mathrm{C}\right)\right)$ are shown in Table III.

\section{Relationship between Vickers Hardness and Hydrogen Content}

Figure 3 shows the relationship between Vickers hardness ratio and hydrogen content. The measurement load is $9.8 \mathrm{~N}$, and the holding time is 30 seconds. The Vickers hardness ratio, $\Phi$, is defined as the ratio of Vickers hardness for a hydrogen-charged specimen $H V_{\mathrm{H} \text {-charged }}$ to the Vickers hardness for an uncharged

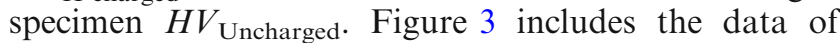
ultimate tensile stress together with Vickers hardness for another type $316 \mathrm{~L}$ stainless steel, having a slightly different chemical composition. The chemical composition is listed in Table I (type $316 \mathrm{~L}^{\dagger}$ ). The Vickers hardness is increased by the presence of hydrogen. For example, the Vickers hardness, $H V=176$ for an uncharged specimen with $C_{\mathrm{H}}=2.2 \mathrm{wt} \mathrm{ppm}$ and $H V=193$ for a supersaturated specimen with $C_{\mathrm{H}}=$ $109.3 \mathrm{wt} \mathrm{ppm}$. The increase in $\Phi$ is almost linearly related to hydrogen content regardless of the type of austenitic stainless steel; the relationship between $\Phi$ and $C_{\mathrm{H}}$ can be expressed as $\Phi=1+9.67 \times 10^{-4} C_{\mathrm{H}}$, where $C_{\mathrm{H}}$ is in wt ppm.

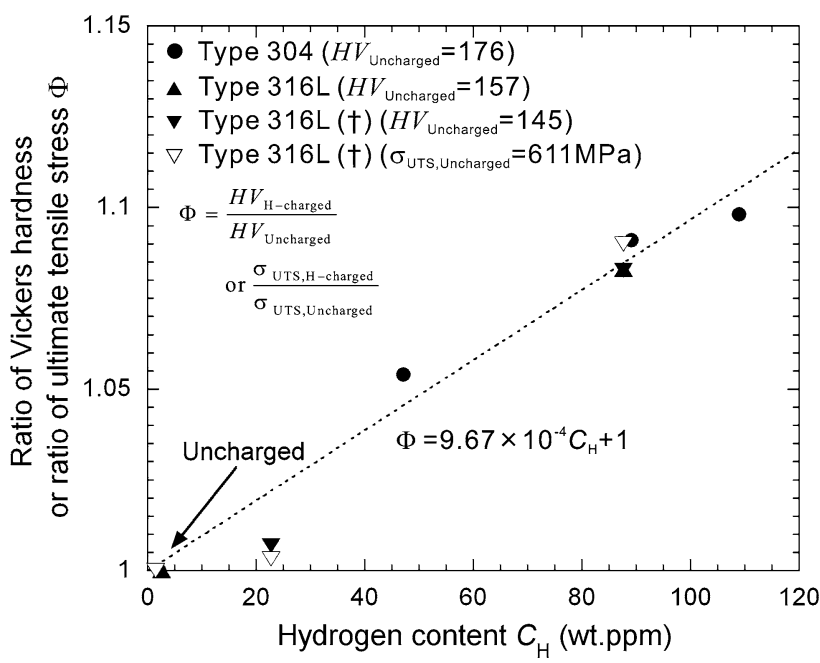

Fig. 3-Relationship between Vickers hardness and hydrogen content.

\section{Method of Fatigue Testing}

In the components of the fuel cell vehicle system, the problem of the small fatigue cracks has been regarded as particularly important. For this reason, the fatigue test of the present study was performed by the use of round bar specimens containing a small artificial defect, the hole (Figure 1). Fatigue tests of the hydrogen-charged and uncharged specimens were carried out at room temperature either in laboratory air or in a hydrogen gas environment. The fatigue tests were conducted at a stress ratio, $R=-1$, by tension-compression cyclic loading (sine wave). The replica method ${ }^{[42]}$ was used for the measurements of crack length and for the observation of crack growth behavior. Following the fatigue tests, in order to measure the hydrogen content remaining in specimens, 0.8 -mm-thick disks were cut from each specimen, under water cooling, immediately after fatigue testing. The hydrogen contents of disks were then measured by TDS.

In this study, the basic mechanism for the effect of hydrogen on slip deformation properties is elucidated by fatigue testing of hydrogen-charged austenitic stainless steels with various hydrogen contents. The important points that are definitely different from the approaches used in previous studies are listed as follows.

(1) Investigation of the effect of hydrogen content on fatigue crack growth properties by changing hydrogen content from an uncharged level to a supersaturated level.

(2) Investigation of the effect of differences in hydrogen content on slip deformation behavior in the vicinity of a fatigue crack tip. Slip localization and planarity are investigated microscopically.

(3) Investigation of the effect of differences in hydrogen content on slip deformation behavior far from a fatigue crack. The relationship between the hydrogen pinning of dislocations and slip band morphology is investigated. The effect of supersaturated 
hydrogen on slip deformation behavior is investigated microscopically.

(4) The relationship between hydrogen diffusion rate and strain rate (dislocation mobility) is investigated by focusing on the effects of test frequency and of hydrogen on fatigue crack growth.

As mentioned in Section I, there are several experimental methods for investigating $\mathrm{HE}$ mechanisms. It will be seen in the following section that the observation of fatigue crack growth behavior, by using the replica method, is most pertinent to visualization of the mechanism of the interaction between hydrogen and dislocations.

\section{RESULTS AND DISCUSSION}

\section{A. Effects of Hydrogen Content and Cyclic Loading Frequency, $f$, on Fatigue Crack Growth Properties}

It is well known that, as a generalization, hydrogen degrades mechanical properties of metals, such as ductility, fracture toughness, fatigue crack growth, etc. This phenomenon is termed "hydrogen embrittlement." However, the results shown in Figure 4 contradict the generalization. The figure shows the surprising effect of hydrogen on fatigue crack growth curves (crack length, $2 a$; and the number of cycles, $N$ ) for type 304. Curve A denotes results for the uncharged specimen, i.e., a solution-treated material; its hydrogen content, $C_{\mathrm{H}}$, is 2.2 wt ppm. Curves B, C, and D show the results for hydrogen-charged specimens. The hydrogen content was measured after fatigue testing: $C_{\mathrm{H}}=23.9 \mathrm{wt} \mathrm{ppm}$ for curve B, $C_{\mathrm{H}}=70.4 \mathrm{wt} \mathrm{ppm}$ for curve $\mathrm{C}$, and $C_{\mathrm{H}}=$ 89.2 wt ppm for curve D. All the tests, shown in Figure 4, were conducted at a cyclic loading frequency, $f$, of $1 \mathrm{~Hz}$.

In curve $\mathrm{C}$, when the crack length, $2 a$, reached $500 \mu \mathrm{m}$, the test environment was changed from air to hydrogen gas (at a pressure of $0.7 \mathrm{MPa}$ ). Nevertheless, it appears that there was no corresponding acceleration in crack growth rates.

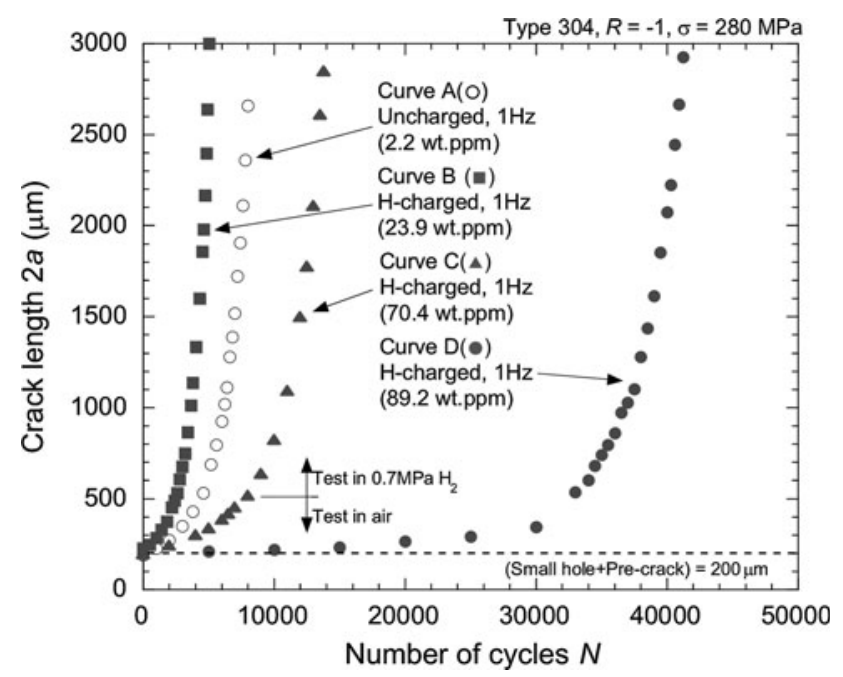

Fig. 4-Effect of hydrogen content on fatigue crack growth.
Crack growth rates for the specimen with $C_{\mathrm{H}}=$ $23.9 \mathrm{wt} \mathrm{ppm} \mathrm{(curve} \mathrm{B)} \mathrm{were} \mathrm{higher} \mathrm{than} \mathrm{those} \mathrm{for} \mathrm{the}$ uncharged specimen (curve A), while in the case of the specimens with $C_{\mathrm{H}}=70.4 \mathrm{wt} \mathrm{ppm}$ (curve C) and $C_{\mathrm{H}}=89.2 \mathrm{wt}$ ppm (curve D), the crack growth rates decreased compared with those of the uncharged specimen, and also with those of the specimen with $C_{\mathrm{H}}=$ $23.9 \mathrm{wt} \mathrm{ppm}$. These results are contrary to the prediction based on the well-known generalization on HE in that supersaturated hydrogen, above a critical content, strongly improves, rather than degrades, fatigue crack growth resistance. The critical hydrogen content over which hydrogen improves fatigue crack growth resistance cannot be precisely determined from Figure 4. However, it is worth noticing that the hydrogen contents, $C_{\mathrm{H}}=70.4 \mathrm{wt} \mathrm{ppm}$ for curve $\mathrm{C}$ and $C_{\mathrm{H}}=89.2 \mathrm{wt} \mathrm{ppm}$ for curve $\mathrm{D}$, are much higher than the saturated hydrogen content, which is in equilibrium for a fatigue test carried out at atmospheric pressure and ambient temperature, i.e., $C_{\mathrm{H}} \approx 0$ wt ppm $\left(0.1 \mathrm{MPa}, 298 \mathrm{~K}\left(25^{\circ} \mathrm{C}\right)\right)$.

All these data were obtained under a stress amplitude $\sigma=280 \mathrm{MPa}$ with round bar specimens having a small hole. Studying the problem of small fatigue cracks behavior has been recognized as more important for the components of a fuel cell vehicle system than the problem of long cracks such as CT specimen. Since substantially the same phenomena were observed under different stress amplitudes, the discussion in this article will be based only on the data for $\sigma=280 \mathrm{MPa}$.

Figure 5 compares fatigue crack growth curves for hydrogen-supersaturated specimens and uncharged specimens of type 304 between in terms of cyclic loading frequency. Murakami et al. ${ }^{[44]}$ found that a very small amount of hydrogen ( 2.2 wt ppm), which was initially contained in uncharged types 304 and 316L stainless steels, increased the fatigue crack growth rate as the test frequency, $f$, was reduced to $0.0015 \mathrm{~Hz}$. In the figure, curves A-1 and A-2 show a similar frequency effect. Hydrogen-supersaturated specimens, with $C_{\mathrm{H}}=$ 70.4 wt ppm, exhibited an increased fatigue crack growth rate as the test frequency decreased from $1 \mathrm{~Hz}$

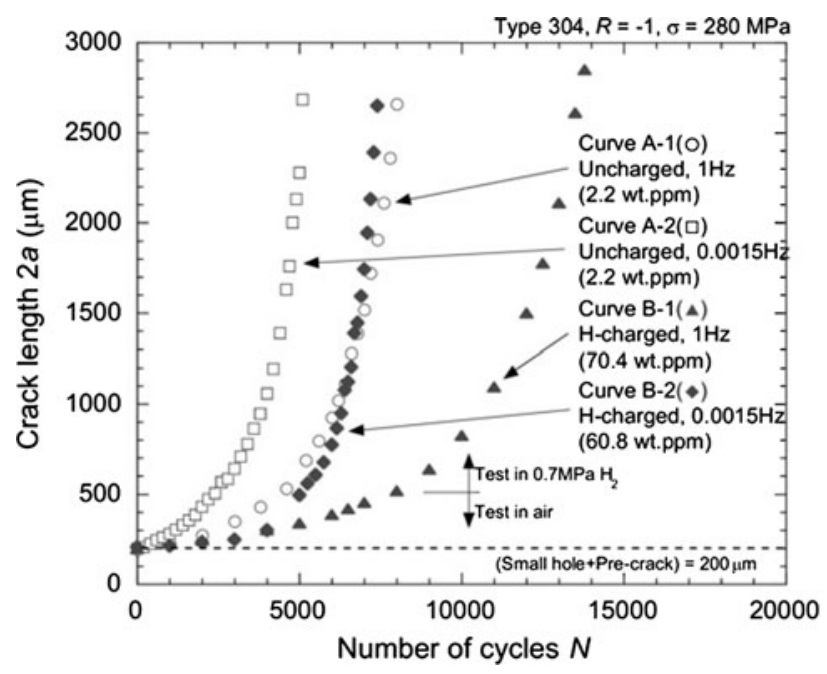

Fig. 5-Effect of test frequency on the fatigue crack growth of a highly hydrogen-charged specimen. 
(curve B-1) to $0.0015 \mathrm{~Hz}$ (curve B-2). It is interesting to note that curve $\mathrm{B}-2$, with $C_{\mathrm{H}}=60.8 \mathrm{wt} \mathrm{ppm}$ and frequency of $0.0015 \mathrm{~Hz}$, is very similar to curve A-1, which was obtained by testing uncharged specimens with $C_{\mathrm{H}}=2.2 \mathrm{wt}$ ppm at a frequency of $1 \mathrm{~Hz}$. Thus, fatigue crack growth resistance can be improved by charging abundant hydrogen into austenitic stainless steels.

Figure 6(a) shows that the increase in hydrogen content increased the fatigue life for crack initiation from a small hole of $100-\mu \mathrm{m}$ diameter. Figure $6(\mathrm{~b})$ shows the extension of the total fatigue life $N_{\mathrm{f}}$ (crack initiation life, $N_{\mathrm{c}}+$ crack propagation life, $N_{\mathrm{p}}$ ) as a function of hydrogen content, $C_{\mathrm{H}}$. Figure 7 represents the effects of the stress intensity factor, $\Delta K$ (Figure $7(\mathrm{a}))$,

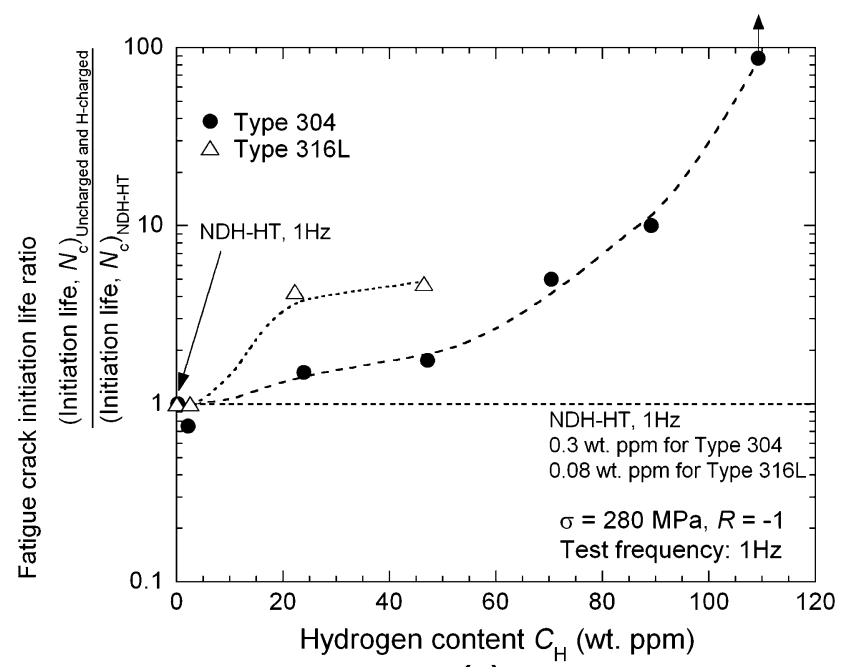

(a)

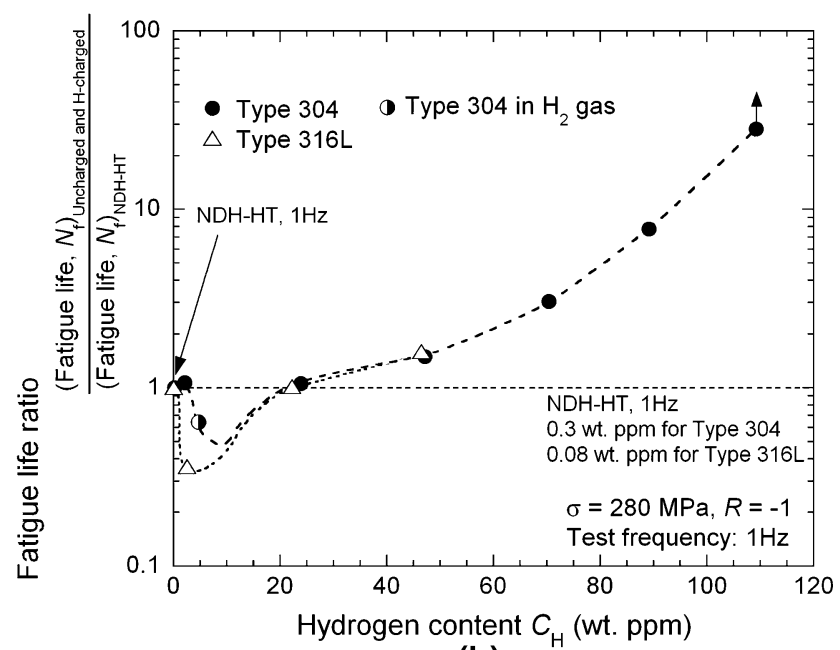

(b)

Fig. 6-(a) Relationship between fatigue crack initiation life ratio ( $N_{\mathrm{c}, \text { Uncharged and H-charged }} / N_{\mathrm{c}, \mathrm{NDH}-\mathrm{HT}}$ ) and hydrogen content, $C_{\mathrm{H}}$. (The fatigue crack initiation life, $N_{\mathrm{c}}$, of NDH-HT specimen for type 304 is 4000 cycles. $N_{\mathrm{c}}$ of NDH-HT specimen for type $316 \mathrm{~L}$ is 11,000 cycles.) (b) Relationship between the fatigue life ratio $\left(N_{f, \text { Uncharged }}\right.$ and H-charged $/ N_{f, \mathrm{NDH}-\mathrm{HT}}$ ) and hydrogen content, $C_{\mathrm{H}}$. (The fatigue life, $N_{f}$, of NDH-HT specimen for type 304 is 12,400 cycles. $N_{f}$ of NDH-HT specimen for type $316 \mathrm{~L}$ is 113,000 cycles.) NDH-HT indicates heat treatment for removing nondiffusible hydrogen. and the hydrogen content, $C_{\mathrm{H}}$ (Figure $7(\mathrm{~b})$ ), on fatigue crack growth rate $d a / d N$. It can be seen in Figure 7 that specimens having hydrogen content $C_{\mathrm{H}} \geq 70.4$ wt ppm have much slower fatigue crack growth rates, over a wide range of crack lengths, than those of the nondiffusible hydrogen desorption heat treated specimen (NDH-HT) specimen (note that the increase in $\Delta K$ corresponds to an increase in crack length, $a$, under constant stress amplitude). The crack growth behavior of small cracks cannot always be characterized by a single parameter such as $\Delta K$. Here, $\Delta K$ is appropriate as a reference parameter, because all the data used in comparisons were obtained under the same stress amplitude, $\sigma=280 \mathrm{MPa}$.

\section{B. Slip Morphology at Fatigue Crack Tips}

Figure 8 shows laser microscopic observations, using the replica method, of slip morphology at crack tips in

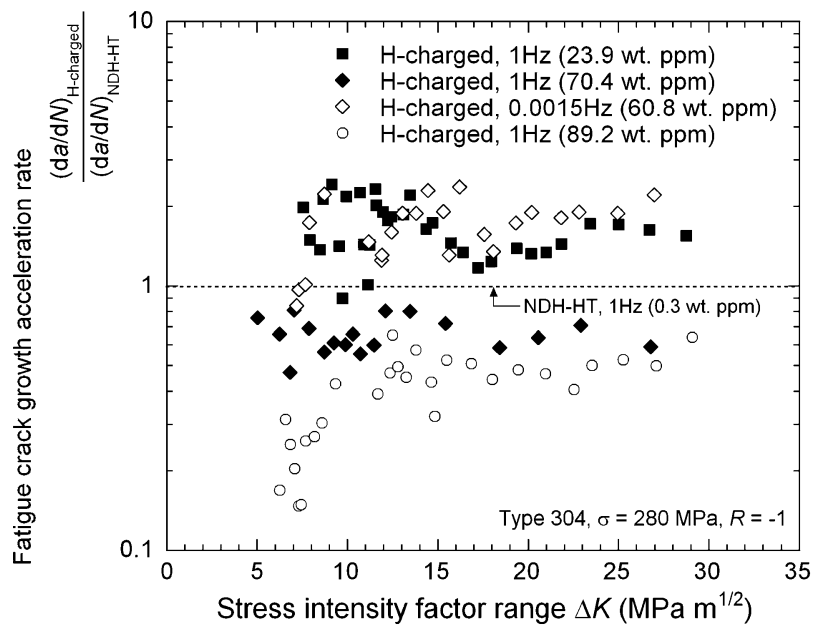

(a)

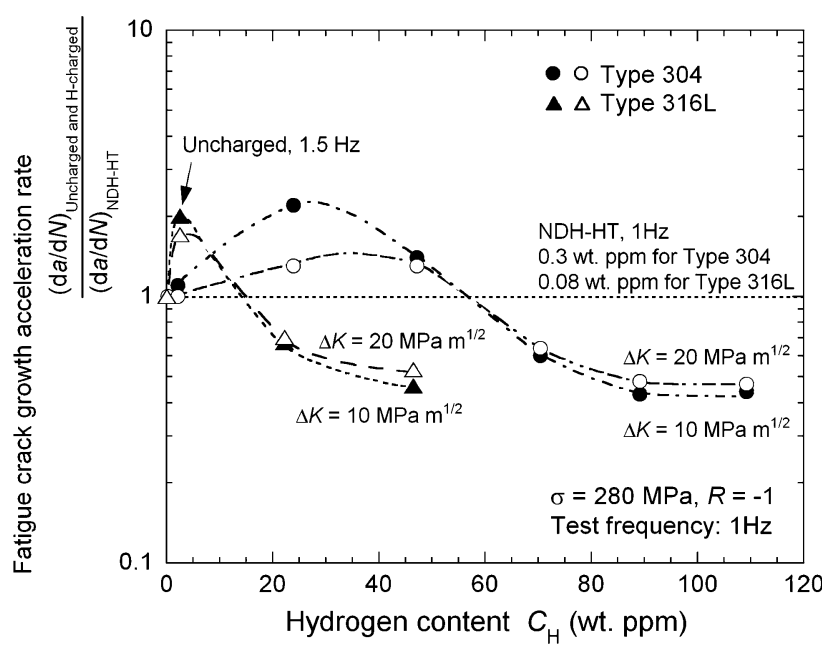

(b)

Fig. 7-(a) Relationship between crack growth acceleration rate and stress intensity factor range $\Delta K$ for type 304 and (b) relationship between crack growth acceleration rate and hydrogen content $C_{\mathrm{H}}$ for types 304 and $316 \mathrm{~L}$. NDH-HT indicates heat treatment for removing nondiffusible hydrogen. 

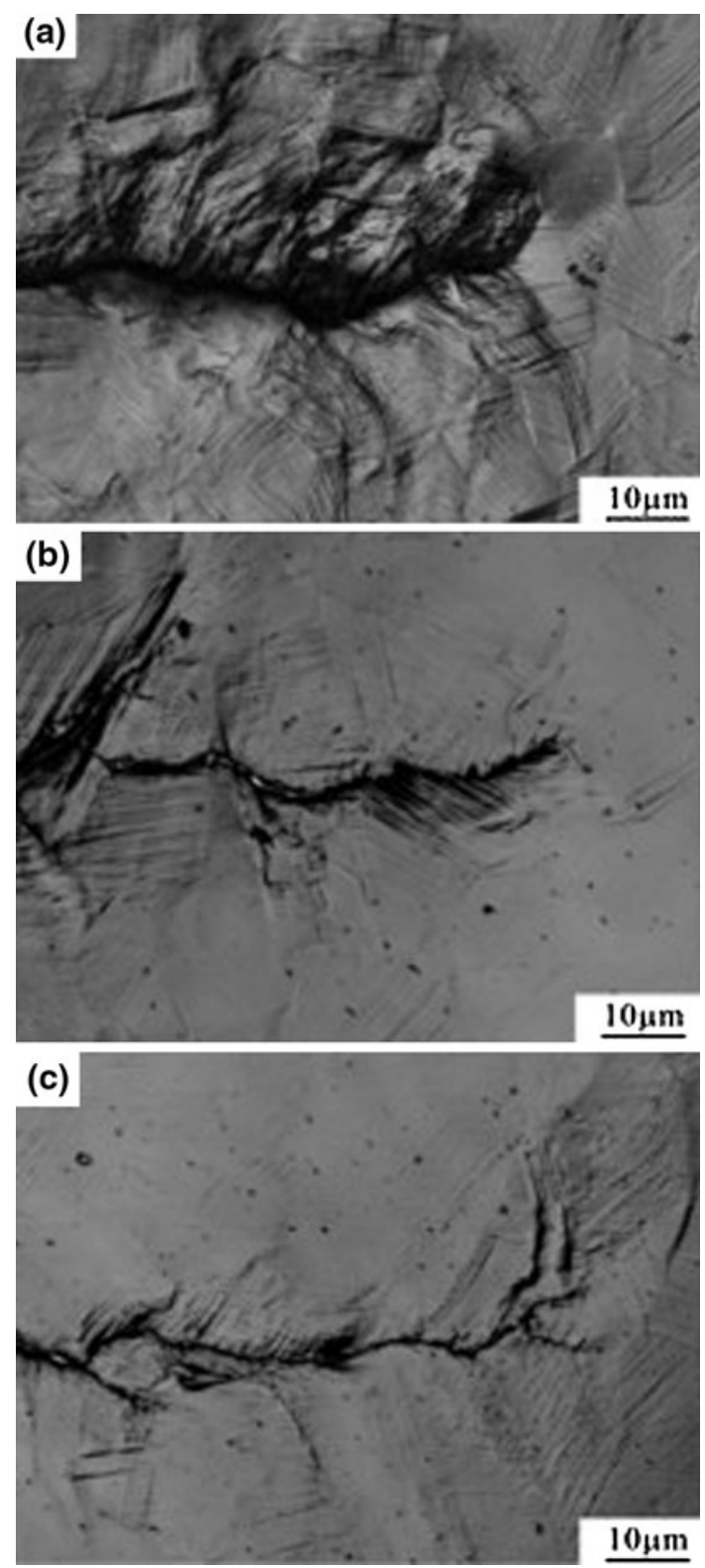

Fig. 8-Slip deformation behavior near fatigue crack in type 304: (a) uncharged type 304 at $1.0 \mathrm{~Hz}\left(C_{\mathrm{H}}=2.2 \mathrm{wt} \mathrm{ppm}, \sigma=280 \mathrm{MPa}\right.$, $N=13,200$, and $2 a=3.019 \mathrm{~mm}$ ), (b) H-charged type 304 at $1.0 \mathrm{~Hz}\left(C_{\mathrm{H}}=47.2 \mathrm{wt}\right.$ ppm, $\sigma=280 \mathrm{MPa}, N=18,400$, and $2 a=$ $2.871 \mathrm{~mm})$, and $(c)$ H-charged type $304 \mathrm{at} 1.0 \mathrm{~Hz} \quad\left(C_{\mathrm{H}}=\right.$ 89.2 wt ppm, $\sigma=280 \mathrm{MPa}, N=96,200$, and $2 a=2.926 \mathrm{~mm})$.

type 304 austenitic stainless steel. These reveal the basic mechanism for the effect of hydrogen on fatigue crack growth behavior. All the images, Figures 8(a) through (c), were taken at crack length $2 a=\sim 3 \mathrm{~mm}$. The uncharged specimen with $C_{\mathrm{H}}=2.2 \mathrm{wt}$ ppm (Figure 8(a)) has widespread and dense slip bands, including cross-slip around the crack tip, while the hydrogen-supersaturated specimen, with $C_{\mathrm{H}}=89.2 \mathrm{wt}$ ppm (Figure 8(c)), exhibits pronounced planar slip localization at the crack tip.

A hydrogen-charged specimen with $\sim 5$ wt ppm $<C_{\mathrm{H}}<\sim 25 \mathrm{wt}$ ppm (not shown) also had a smaller
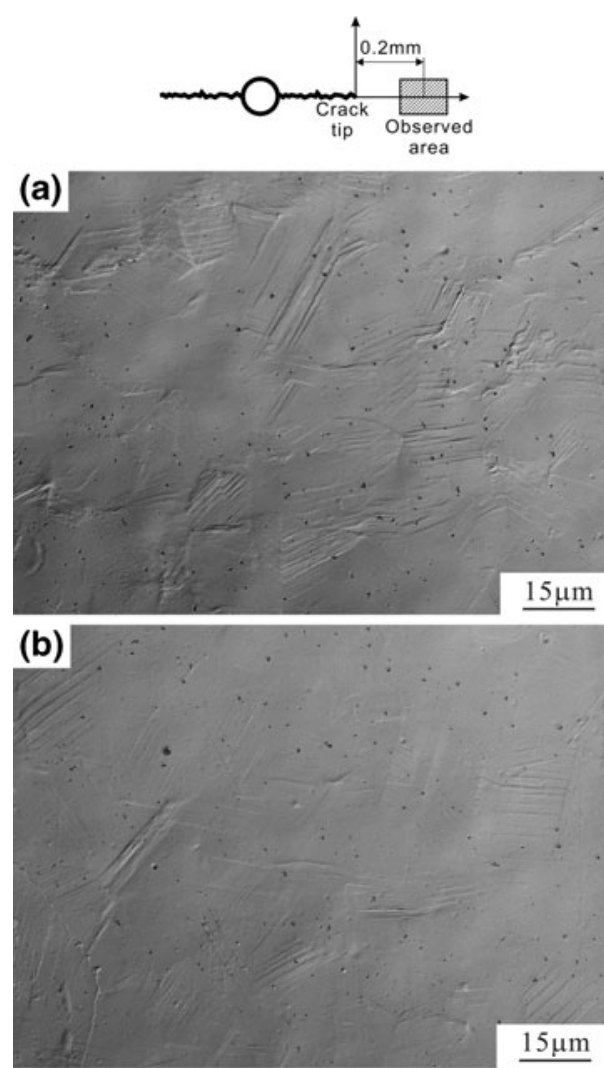

(c)

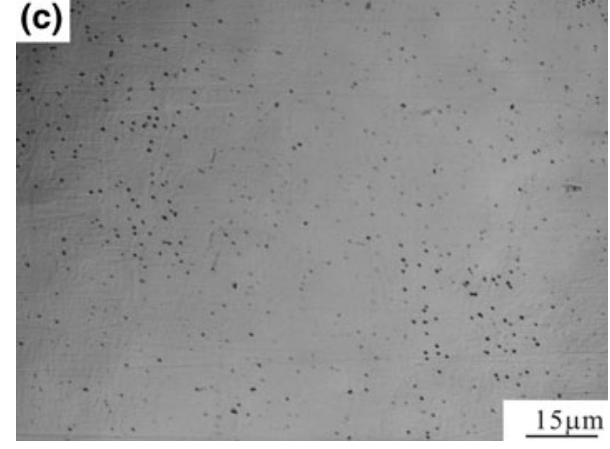

Fig. 9-Slip deformation behavior remote from fatigue crack in type 304. (a) Uncharged type 304 at $1.0 \mathrm{~Hz}\left(C_{\mathrm{H}}=2.2 \mathrm{wt} \mathrm{ppm}, \sigma=\right.$ $280 \mathrm{MPa}, N=13200$, and $2 a=3.019 \mathrm{~mm}$ ), (b) H-charged type 304 at $1.0 \mathrm{~Hz}\left(C_{\mathrm{H}}=47.2 \mathrm{wt} \mathrm{ppm}, \sigma=280 \mathrm{MPa}, N=18,400\right.$, and $2 a=2.871 \mathrm{~mm})$, and $(c)$ H-charged type 304 at $1.0 \mathrm{~Hz}\left(C_{\mathrm{H}}=\right.$ 89.2 wt ppm, $\sigma=280 \mathrm{MPa}, N=96200$, and $2 a=2.926 \mathrm{~mm}$ ).

slip region at a crack tip, as compared with the uncharged specimen. In this case, however, the fatigue crack growth rates of the hydrogen-charged specimen were much higher than those of the uncharged specimen; this is typical of HE. The reason and mechanism for this hydrogen-induced fatigue crack growth acceleration was explained by Murakami et al..$^{[44]}$

Figure 9 shows that, in hydrogen-charged specimens, there are very few slip bands remote from a fatigue crack. This is more clearly demonstrated in Figure 10, which is at a lower magnification. Thus, slip band morphology and slip band density are essentially the same in hydrogen-supersaturated specimens, with $C_{\mathrm{H}}>$ $\sim 47 \mathrm{wt} \mathrm{ppm}$, and in specimens with $\sim 5 \mathrm{wt} \mathrm{ppm}<C_{\mathrm{H}}$ 
$<\sim 47$ wt ppm, in which fatigue crack growth rates are accelerated by hydrogen.

The preceding experimental facts can be summarized as follows.

(1) Hydrogen accelerates fatigue crack growth rates when the hydrogen content is $\sim 5$ wt ppm $<C_{\mathrm{H}}$ $<\sim 47 \mathrm{wt}$ ppm for type 304 and $\sim 2 \mathrm{wt}$ ppm $<C_{\mathrm{H}}$ $<\sim 15 \mathrm{wt} \mathrm{ppm}$ for type 316L (Figure 7).

(2) Supersaturated hydrogen with $C_{\mathrm{H}}>\sim 25 \mathrm{wt} \mathrm{ppm}$ significantly prolongs fatigue life (Figure 6).

(3) Slip localization morphology at a crack tip and slip band density are essentially the same, regardless of hydrogen content, for specimens with $C_{\mathrm{H}}$ $\sim 5$ wt ppm $<C_{\mathrm{H}}<\sim 47 \mathrm{wt} \mathrm{ppm}$ and for specimens with $C_{\mathrm{H}}>\sim 47$ wt ppm.

The preceding experimental facts, (1), (2), and (3), appear to be contradictory. Therefore, to resolve the mystery of HE, it is crucially important to investigate the relationship between hydrogen content and slip behavior, i.e., the interaction between hydrogen and dislocations.

\section{Two Aspects of Hydrogen-Dislocation Interaction: the Hardening Effect and the Softening Effect}

Extensive research has been done on the interaction between hydrogen and dislocations. ${ }^{[5,22-24,26,36-41,48]}$ Reviewing these articles, it seems that there is a general consensus that the basic process of HE should be related to the effect of hydrogen on dislocation motion.

This consensus among existing researchers is, in turn, based on another consensus: that hydrogen always degrades the mechanical properties of metallic materials, particularly fatigue resistance and fracture toughness. However, there are two, puzzling, contradictory aspects of hydrogen-dislocation interaction: first, there are more reports of hydrogen-enhanced hardening than softening; and, second, the increased mobility of dislocations, i.e., the decreased line energy or line tension. ${ }^{[36-39]}$ There are also contradictory arguments on slip planarity due to the decrease in stacking fault energy (SFE). ${ }^{[49,50]}$ Sofronis et al. ${ }^{[5]}$ and Chateau et al. ${ }^{[48]}$ suggested that the decrease in interaction energy between dislocations is the reason for microscopic softening.

Gavriljuk et al. ${ }^{[38,39]}$ considered that the increased density of free electrons around the dislocations, due to hydrogen, decreases the shear modulus and eventually brings about a decreased critical shear stress for dislocation movement, and also decreased dislocation line tension, i.e., the interaction distance in dislocation pileups.

Kirchheim et al. ${ }^{[36,37]}$ pointed out two aspects of hydrogen effects: on one hand, hydrogen-enhanced dislocation mobility is caused by decreased line energy due to the presence of hydrogen; while, on the other hand, hydrogen has a dragging effect on dislocations.

Sofronis ${ }^{[51]}$ showed analytically that the interaction between two edge dislocations is reduced when the hydrogen in solution reaches equilibrium with the local stress. In terms of hydrogen content, Sofronis and Birnbaum $^{[52]}$ found the trend increases with increasing nominal hydrogen content. The group of Birnbaum ${ }^{[5,51,53]}$ stated that screening stresses from obstacles by hydrogen is the physical basis of the hydrogen-enhanced localized plasticity (HELP) model for HE.

Previous studies have not been able to fully explain hydrogen effects of HE. This is because hydrogendislocation interaction effects have been investigated and discussed only on the basis of either simple tensile tests or internal friction tests. This article resolves the mystery of the two contradictory aspects of hydrogendislocation interactions through microscopic observation of fatigue crack growth behavior and of cyclic slip behavior.

Both the peculiar fatigue crack growth behaviors and varying crystallographic slip morphologies, over a wide range of hydrogen content, $C_{\mathrm{H}}$, can be explained without any contradiction, by considering the two opposing effects of hydrogen on dislocation motion.
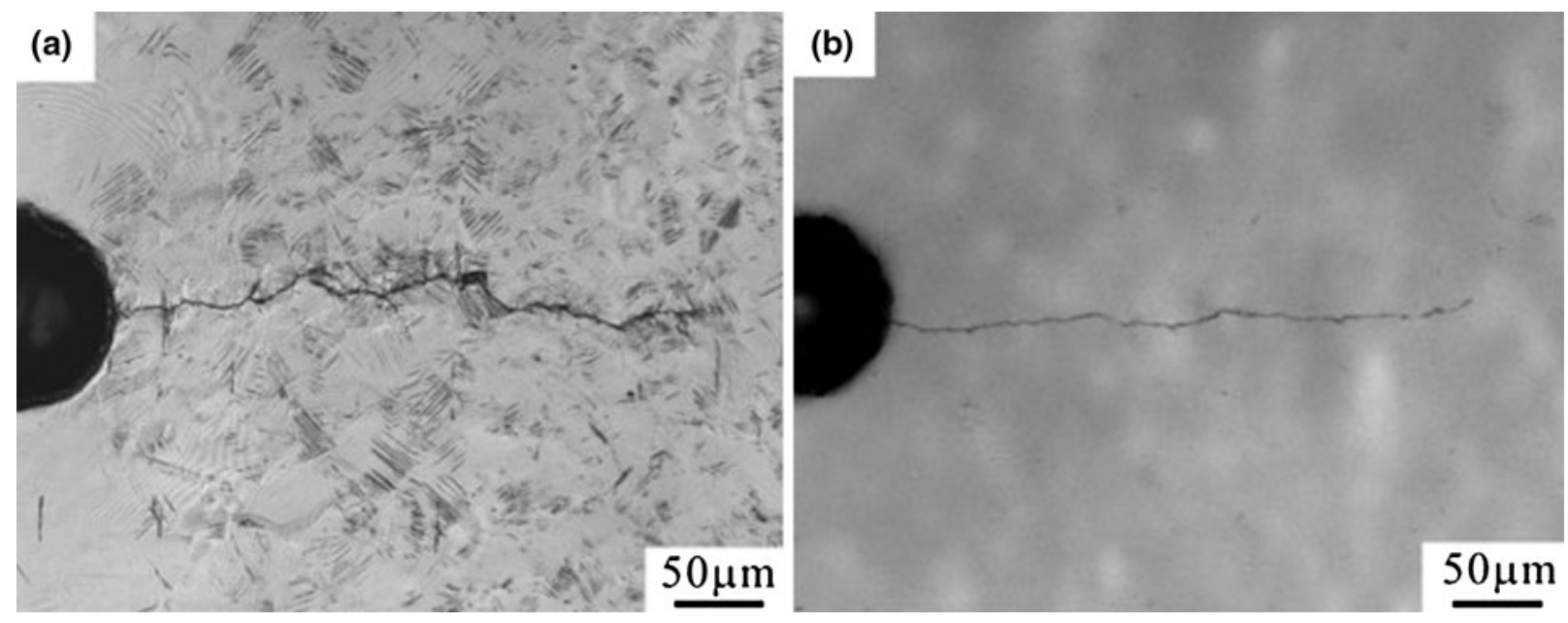

Fig. 10-Macroscopic observation of slip deformation behavior around fatigue crack. (a) Uncharged type 304 at $1.0 \mathrm{~Hz}\left(C_{\mathrm{H}}=2.2 \mathrm{wt}\right.$ ppm, $\sigma=280 \mathrm{MPa}, N=11,000$, and $2 a=0.782 \mathrm{~mm})$, and $(b) \mathrm{H}$-charged type 304 at $1.0 \mathrm{~Hz}\left(C_{\mathrm{H}}=89.2 \mathrm{wt} \mathrm{ppm}, \sigma=280 \mathrm{MPa}, N=92,000\right.$, and $2 a=1.028 \mathrm{~mm})$. 
Figure 11(a) illustrates the pinning effect of hydrogen on a dislocation. The hydrogen trapped by a dislocation increases the critical shear stress for dislocation glide. Hydrogen trapped at a dislocation core, in a dilatational stress field, pins an edge dislocation. ${ }^{[41]}$ The higher the hydrogen concentration, the stronger the pinning effect. It follows that if the hydrogen concentration at dislocation is supersaturated, then the pinning effect should be particularly strong.

This pinning effect contributes to increasing the strength of materials. The effect explains why there are fewer grains with slip bands in the case of specimens with high hydrogen content, $C_{\mathrm{H}}$, as shown in Figures 8 and 9 . Sofronis ${ }^{[51]}$ showed analytically that hydrogen decreases the interaction energy between dislocations. The analytical model can work both for slip localization (local softening) and for hardening in the region larger than a grain. Figure 12 shows variations in the cyclic

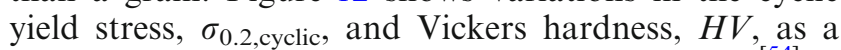
function of the hydrogen content for type $316 \mathrm{~L} \cdot{ }^{[54]} \mathrm{It}$ has been reported that hydrogen charging increases static flow stress. ${ }^{[27,33-35]}$ Figure 12 shows also the increase in Vickers hardness measured at a $9.8-\mathrm{N}$ load with increasing hydrogen content. However, the effect of hydrogen on the cyclic yield stress in terms of hydrogen

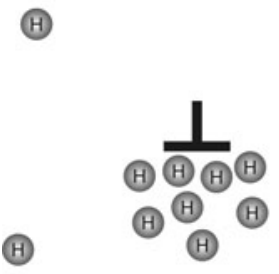

(a)

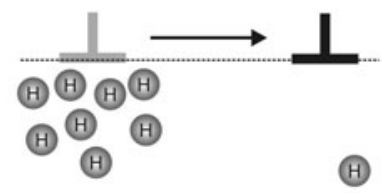

(b)
Fig. 11-Schematic illustration of the interaction between hydrogen and dislocation.

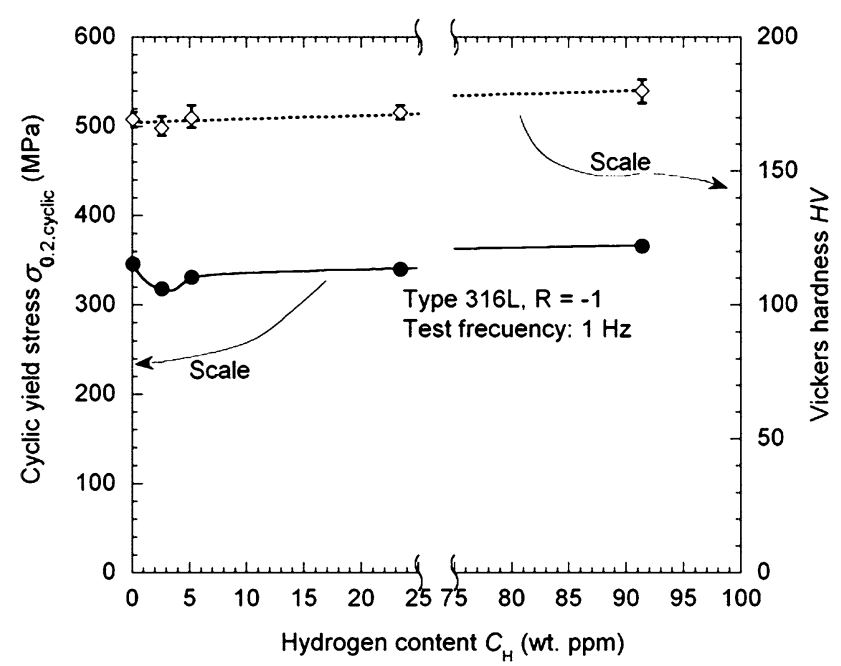

Fig. 12-Relationships of the cyclic yield stress and the Vickers hardness with hydrogen content for type $316 \mathrm{~L} . \sigma_{0.2, \text { cyclic: }} 0.2 \mathrm{pct}$ proof stress in cyclic stress-strain curve. content is not simple, particularly at low hydrogen content as for the case of fatigue life (Figures 6 and 7).

Moriya et al. ${ }^{[11]}$ reported that hydrogen, which is cathodically charged at a certain strain during a tensile test, resulted in softening. However, it must be noted that cathodic charging always creates a hydrogen concentration gradient from a specimen surface to the subsurface, and also that subsurface dislocations do not trap hydrogen before hydrogen charging. Thus, if we employ cathodic charging, we cannot avoid the trigger effect of surface hydrogen on the start of slip, and also on the subsequent complicated stress-strain curve.

On the other hand, Murakami et al. ${ }^{[44]}$ and Kanezaki et al. ${ }^{[45]}$ showed that the fatigue crack growth rates of hydrogen-charged types 304, 316, and 316L austenitic stainless steels are higher than those of uncharged specimens and, more importantly, testing at decreased frequency, $f$, down to $f=0.0015 \mathrm{~Hz}$, enhances the hydrogen effect. Murakami et al. ${ }^{[44]}$ found that even the small amount of hydrogen, of the order of 2 to 3 wt ppm, contained in uncharged specimens of austenitic stainless steels has a damaging effect on fatigue crack growth at the very low load frequency of $f=$ $0.0015 \mathrm{~Hz}$. A model has been proposed by Murakami et al. ${ }^{[44]}$ to explain this peculiar frequency effect.

In the present study, expecting a stronger hydrogen effect, supersaturated hydrogen was charged at high temperature and high pressure into types 304 and $316 \mathrm{~L}$ stainless steels, and fatigue tests were carried out at room temperature and $1 \mathrm{~Hz}$. However, surprisingly, fatigue crack growth rates for these specimens were dramatically decreased, as shown in Figure 4.

Summarizing the experimental results of the present study, the following two phenomena require attention.

(1) Fatigue crack growth rates are decreased both at extremely low hydrogen content ${ }^{[44]}$ and at high, supersaturated, hydrogen content, $C_{\mathrm{HS}}$. Thus, damaging hydrogen effects appear for a hydrogen content, $C_{\mathrm{H}}$, above that of the solution-treated state ( 2 to $3 \mathrm{wt} \mathrm{ppm}$ ), but below the supersaturated value, $C_{\mathrm{Hs}}$. In other words, undesirable effects of hydrogen appear over a certain range of $C_{\mathrm{H}}$.

(2) Although we do not have precise information on dislocation pinning due to hydrogen in fcc metals, it is presumed from the experimental results of the present study that dislocation pinning due to hydrogen occurs when hydrogen atoms are trapped in a dislocation core within a dilatational stress field. We may need to plan more different experiments to reveal the detailed mechanism. If the applied shear stress is above a critical value, then dislocations are unpinned, and dislocation mobility is increased. Reconsideration of the experiments of Birnbaum et al. (References 22 through 24) provides another example of the same interaction effect between hydrogen and dislocations. In their experiments, hydrogen was supplied to thin specimens under a tensile stress within a TEM cell; we must note that at the beginning of a test in the TEM cell, the dislocations in a thin specimen are not initially pinned by hydrogen. The observation 
of increased dislocation mobility in the internal friction tests of Gavriljuk et al. ${ }^{[38,39]}$ also indicates a softening effect, not by the initially stationary dislocations, but by interaction between hydrogen atoms and mobile dislocations that have been released from pinning by hydrogen. It follows that the basic mechanism of the phenomenon observed by Birnbaum et al. is essentially the same as that observed by Gavriljuk et al.

Figure 11(b) illustrates hydrogen atoms left behind an edge dislocation core after it is released from pinning and moves (Figure 11(a)). Although these hydrogen atoms move with time toward another dislocation core within a dilatational stress field (molecular dynamic analysis by Kakimoto ${ }^{[55]}$ ), the dislocation mobility is enhanced as long as these dislocations are located apart from the latter dislocation (molecular dynamics analysis by Taketomi et al. ${ }^{[56]}$ ).

Under this condition, a dislocation continues to move at a lower stress than the critical shear stress necessary to release a dislocation that has been pinned by hydrogen. Such a dislocation movement activates Frank-Read sources and generates additional new dislocations; slip is confined to planes and, in the presence of solute hydrogen, cross-slip is prevented. By contrast, in the same specimen, further slip does not originate at dislocations that have not been released from pinning by hydrogen. The chain reaction of hydrogen-dislocation interaction is presumed to be the cause of slip localization at fatigue crack tips. Sofronis ${ }^{[51]}$ and Sofronis and Birnbaum $^{[52]}$ analyzed the problems of the interaction between dislocations and hydrogen atoms distributed at the dilatation area of edge dislocations. In a similar analysis, Chateau et al. ${ }^{[48]}$ also reported a decrease in interaction energy between co-planar dislocations. The HELP model, which emphasizes screening stress from obstacles by hydrogen atmospheres, may be the most important basic model to explain the interaction between hydrogen and mobile dislocations. However, the fatigue crack growth rate dramatically changes depending on hydrogen content, e.g., much decreased crack growth rate for the cases of almost zero $\mathrm{H}$ content and supersaturated $\mathrm{H}$ content and increased crack growth rate for the case of a few ppm H content (Figure 7). In order to explain, without contradiction, the experimental results of the present study (supersaturated hydrogen), and also the results of the previous experiments ${ }^{[44]}$ (almost no hydrogen), it is necessary to consider the way of application of the HELP model to fatigue phenomena in relation to hydrogen content and fatigue crack growth mechanism. If we interpret that the HELP model acts inside the fatigue process zone at crack tip and the zone outside the process zone does not satisfy the critical condition of slip, the phenomena can be understood without contradiction.

The supersaturated hydrogen in the aforementioned mechanism influences the size of the plastic zone at a fatigue crack tip, as shown in Figure 13. Murakami et al. ${ }^{[44]}$ presented a model for fatigue crack growth in the presence of hydrogen. Their model showed that, in the presence of hydrogen, a growing fatigue crack has a

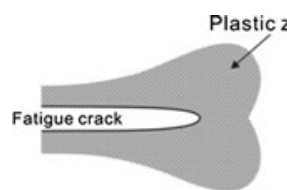

(a)

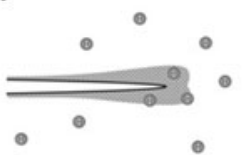

(b)

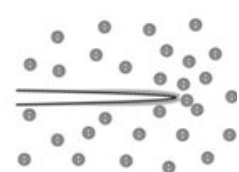

(c)

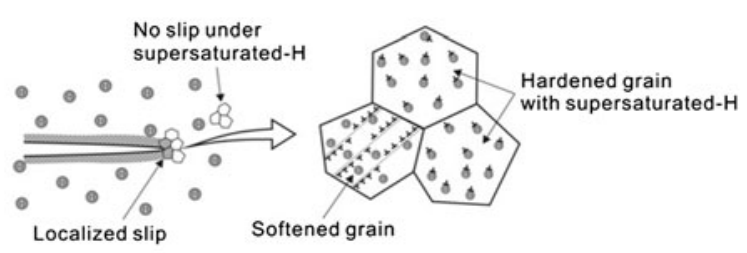

(d)

Fig. 13-Schematic illustration of plastic deformation in the vicinity of fatigue crack tip of $(a)$ uncharged specimen, $(b)$ a H-charged specimen, $(c)$ a specimen with supersaturated hydrogen, and $(d)$ image of slip localization and slip-blocking effects by surrounding hardened grains near a crack tip.

smaller plastic zone size and a smaller crack tip opening displacement than in the absence of a hydrogen effect.

In the supersaturated hydrogen condition, it is natural to presume that the plastic zone size at a fatigue crack tip is strongly limited by additional constraint produced by the increased yield stress, outside the plastic zone, due to dislocation pinning by hydrogen. Consequently, slip displacement at a crack tip is limited by a zone that encircles the plastic zone. Cross-slip at the crack tip is also restricted for the same reason. Hence, planarity of slip is maintained regardless of variations in SFE. It must be noted that these mechanisms, i.e., slip localization inside the plastic zone at a fatigue crack tip, are consistent with the HELP model.

With respect to the hydrogen-dislocation interaction, the effect of the frequency, $f$, of fatigue loading is also important. Although the degree of the frequency effect naturally depends on the hydrogen content, $C_{\mathrm{H}}$, a general tendency is for an increase in fatigue crack growth rate with decreasing $f$, but there is an upper limit to the effect of hydrogen on fatigue crack growth acceleration (Figure 14 and References 19 and 57). The reason for the existence of an upper limit is as follows. With decreasing $f$, hydrogen diffuses into, and concentrates within, the zone of the hydrostatic tensile stress field at a crack tip. In this diffusion process, in which hydrogen travels before being trapped by dislocations, hydrogen atoms enhance dislocation mobility, producing both slip concentration and localization. If $f$ is decreased to very low values, hydrogen atoms are likely to be trapped at dislocation cores and, hence, hinder dislocation motion by a pinning effect. Thus, the decrease in $f$ causes the phenomenon of slip blocking and eventually retards fatigue crack growth rate acceleration. Although essentially same phenomenon occurs in bcc metals, ${ }^{[19]}$ the diffusion rate of hydrogen in bcc metals is four orders higher and, accordingly, the lower content of stable hydrogen in bcc metals, compared with fcc metals, results in a very different frequency effect. 


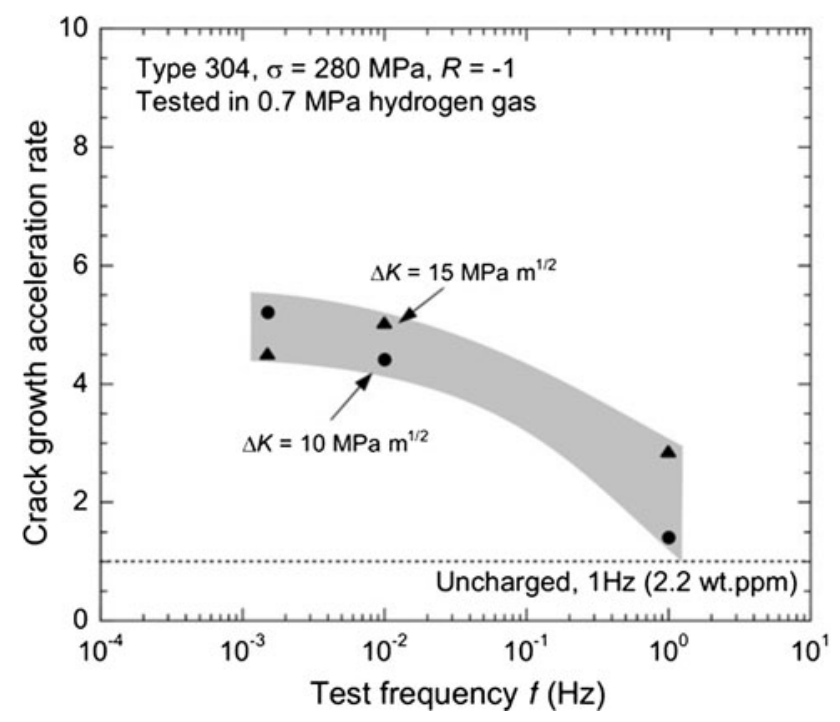

Fig. 14-Relationship between crack growth acceleration rate and test frequency. (Uncharged type 304 tested in $0.7 \mathrm{MPa}$ hydrogen gas. The initial value of $C_{\mathrm{H}}=2.2 \mathrm{wt} \mathrm{ppm).}$

\section{Influence of External Hydrogen}

The different effects of external hydrogen and of internal hydrogen are of scientific interest and are also of practical importance. Here, external hydrogen is defined as the hydrogen that diffuses into a material, through a specimen surface, from $\mathrm{H}_{2}$ gas outside the specimen, during a fatigue test. Internal hydrogen is defined as the hydrogen that is charged into a specimen before mechanical testing. It is known that, in general, external hydrogen diffuses into a material following Sieverts' law. It can be seen from Figure 5 that when a specimen contains supersaturated internal hydrogen, external hydrogen due to $0.7 \mathrm{MPa}$ hydrogen gas has little influence. There are two possible reasons for this result. One is that supersaturated internal hydrogen has a stronger effect of blocking the extension of the plastic zone at the crack tip than does the hydrogen-enhanced slip localization effect caused by the external hydrogen. The other, more probable reason is that the hydrogen content in the material is already supersaturated before fatigue testing in $\mathrm{H}_{2}$ gas at $0.7 \mathrm{MPa}$ and room temperature $\left(C_{\mathrm{HS}}=5.1 \mathrm{wt} \mathrm{ppm}\right)$, and it is therefore thermophysically very difficult for external hydrogen to diffuse into the material.

On the other hand, fatigue crack growth rates for an uncharged specimen tested in $0.7 \mathrm{MPa} \mathrm{H}_{2}$ gas, at $f=0.01 \mathrm{~Hz}$, are much higher than those for an uncharged specimen tested in air. This is because the hydrogen content, $C_{\mathrm{H}}$, of the uncharged specimen is much lower than the hydrogen content for the supersaturated condition, and external hydrogen can enter through the new, fresh surfaces of a crack as hydrogen atoms, $\mathrm{H}$.

Figure 15 shows the EBSD observations of the strain-induced martensite produced in the vicinity of a fatigue crack, where there is severe cyclic deformation as fatigue crack growth proceeds. Figure 15(a) shows
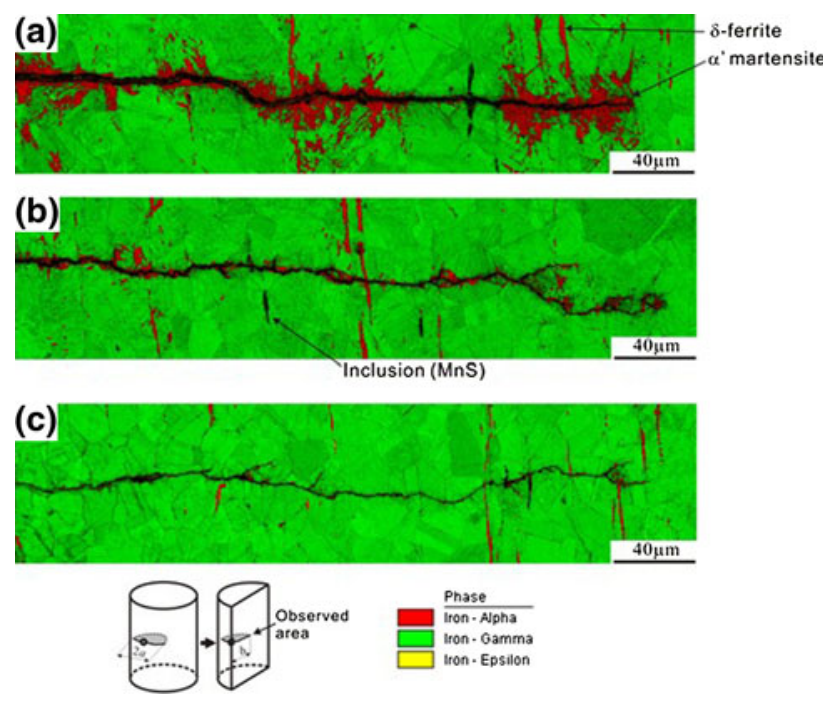

Fig. 15-Martensitic transformation near fatigue crack in type 304. (a) Uncharged specimen tested in air at $1.0 \mathrm{~Hz}\left(C_{\mathrm{H}}=2.2 \mathrm{wt} \mathrm{ppm}\right.$, $\sigma=280 \mathrm{MPa}, 2 a=3.019 \mathrm{~mm}$, and $N=8200$ from $2 a=0.2 \mathrm{~mm}$ ). (b) Uncharged specimen tested in $0.7 \mathrm{MPa} \mathrm{H}_{2}$ at $0.01 \mathrm{~Hz}\left(C_{\mathrm{H}}=\right.$ $2.4 \mathrm{wt} \mathrm{ppm}, \sigma=280 \mathrm{MPa}, 2 a=3.093 \mathrm{~mm}$, and $N=2450$ from $2 a=0.2 \mathrm{~mm}$ ). (c) H-charged specimen tested in air at $1.0 \mathrm{~Hz}$ $\left(C_{\mathrm{H}}=109.3 \mathrm{wt} \mathrm{ppm}, \quad \sigma=280 \mathrm{MPa}, 2 a=3.019 \mathrm{~mm}\right.$, and $N=$ 32,600 from $2 a=0.2 \mathrm{~mm}$ ).

strain-induced martensite in an uncharged specimens $\left(C_{\mathrm{H}}=2.2 \mathrm{wt} \mathrm{ppm}\right)$ tested in air at $f=1 \mathrm{~Hz}$. With little hydrogen effect, martensite was produced extensively, reflecting severe cyclic plastic deformation, including cross-slip.

Figure 15(b) shows the small amount of straininduced martensite in an uncharged specimen $\left(C_{\mathrm{H}}\right.$ of the internal hydrogen $=2.2 \mathrm{wt} \mathrm{ppm}$ ) tested in $0.7 \mathrm{MPa}$ $\mathrm{H}_{2}$ gas at $f=0.01 \mathrm{~Hz}$. This condition definitely brought about slip localization due to a hydrogen effect. Although in this case the martensitic transformation is limited to a small area in the vicinity of the crack, the fatigue crack growth rates are higher than those of an uncharged specimen tested in air at $f=1 \mathrm{~Hz}$.

Figure 15 (c) shows martensitic transformation limited to an extremely small area due to the effect of the supersaturated hydrogen $\left(C_{\mathrm{H}}=109.3 \mathrm{wt} \mathrm{ppm}\right)$. This increased the flow stress outside the plastic zone and blocked the extension of the slip zone, resulting in very low fatigue crack growth rates. All these observations are consistent with slip morphologies in the vicinity of cracks, as shown in Figure 8.

Figure 16 shows typical fatigue fracture surfaces of the specimens supersaturated with a hydrogen content of 47.2 and $89.2 \mathrm{wt}$ ppm for type 304 stainless steel. The fracture surfaces of the hydrogen-supersaturated specimens are less covered with clear striations than those of the specimen with a low hydrogen content. ${ }^{[45]}$ This implies that an increase in the hydrogen content confines the plasticity in a smaller zone at the crack tip so that the formation of striation becomes difficult.

The data presented in this article verify the possibility of increasing fatigue strength by precharging hydrogen to a supersaturated level. Thus, the hydrogen 



Fig. 16-Fatigue fracture surfaces of hydrogen-supersaturated specimens for type 304 stainless steel: $(a) \quad C_{\mathrm{H}}=47.2 \mathrm{wt}$ ppm, $\Delta K=21.4 \mathrm{MPa} \cdot \mathrm{m}^{1 / 2}$, and $d a / d N \cong 0.7 \mu \mathrm{m} ;$ (b) magnification of (a); (c) $C_{\mathrm{H}}=89.2 \mathrm{wt} \mathrm{ppm}, \Delta K=29.1 \mathrm{MPa} \cdot \mathrm{m}^{1 / 2}$, and $d a / d N \cong 0.6 \mu \mathrm{m}$. (d) Magnification of (c). Arrows indicate the crack propagation direction.

effect is not always damaging and we can term a nondamaging hydrogen effect as "hydrogen effect against hydrogen embrittlement." This phenomenon is unique to fcc austenitic stainless steels with the supersaturated hydrogen tested under cyclic loading. In bcc metals, it is difficult to keep the supersaturated hydrogen within the lattice, since the hydrogen diffusivity is high and hydrogen escapes from the material quickly. It is also difficult to perform a fatigue test using such a hydrogen-supersaturated specimen for bcc metals. Actually, the supersaturated hydrogen would not be generated in the service conditions used for components of bcc metals. Although the lattice of the austenitic stainless steels would not be supersaturated with hydrogen in service, it is possible to achieve the hydrogen supersaturation by artificial high-pressure hydrogen gas charging at a temperature higher than in service. Even after taking specimens out of an autoclave at a high pressure and at a medium temperature, the supersaturated hydrogen hardly diffuses from the austenitic stainless steels for a long period. This is due to the difference in the lattice structure between fcc and bcc and lower diffusivity in fcc than bcc by four orders of magnitude.

\section{CONCLUSIONS}

In order to investigate the basic mechanism of HE, fatigue tests were carried out on type 304 and type 316L austenitic stainless steels that contained hydrogen from low to supersaturated levels. The hydrogen was charged in a high-pressure $\mathrm{H}_{2}$ gas autoclave at high temperature in order to avoid the surface effects of cathodic charging. In particular, the attention was focused on the effects of hydrogen on fatigue crack growth behavior, and on microscopic slip localization at crack tips and also in grains remote from crack tips. The results obtained were completely different from those expected from the well-known generalization that hydrogen degrades mechanical properties of metals.

Surprisingly, a supersaturated hydrogen content remarkably increased the fatigue strength. The conclusions can be summarized as follows.

1. The Vickers hardness increased with increasing the hydrogen content, $C_{\mathrm{H}}$, i.e., $H V=176$ for an uncharged specimen with $C_{\mathrm{H}}=2.2 \mathrm{wt} \mathrm{ppm}$ and $H V=193$ for a supersaturated specimen with $C_{\mathrm{H}}=109.3 \mathrm{wt} \mathrm{ppm}$. The relationship between $\Phi$ $\left(\Phi=H V_{\mathrm{H} \text {-charged }} / H V_{\text {Uncharged }}\right)$ and $C_{\mathrm{H}}$ can be 
expressed as $\Phi=1+9.67 \times 10^{-4} C_{\mathrm{H}}$. This relationship is consistent with the results of many other results in the literature that report a hardening effect due to hydrogen, rather than a softening effect. The cause of the increase in $H V$ is presumed to be a dislocation pinning effect.

2. Cyclic slip appeared in many grains of an uncharged specimen $\left(C_{\mathrm{H}}=2.2 \mathrm{wt} \mathrm{ppm}\right)$, but under the same stress amplitude, very few slip bands were observed in a charged specimen. This phenomenon for the case of hydrogen content higher than a critical value is also due to the hardening effect of hydrogen.

3. Many slip bands, including cross-slip, were observed adjacent to the fatigue crack in an uncharged specimen, together with much strain-induced martensite, while the slip bands in a hydrogen-charged specimen were localized, with less cross-slip and less straininduced martensite at the crack tip.

4. Up to a certain critical value of $C_{\mathrm{H}}$, fatigue crack growth rates increased compared with those for an uncharged specimen. However, above the critical value of $C_{\mathrm{H}}$, fatigue crack growth was retarded, and the fatigue strength was markedly improved. This phenomenon should be denoted as "hydrogen effect against HE."

5. The mysterious phenomena of (1) through (4) can be explained as an interaction between hydrogen and dislocations, without contradicting hardening and softening effects reported in the existing literature. Hydrogen trapped at a dislocation core hinders dislocation motion. Once a dislocation is released from pinning by hydrogen at its core, then the dislocation mobility is increased. However, as the value of $C_{\mathrm{H}}$ increases, the extension of the plastic zone at a crack tip is blocked by the surrounding material, which has a higher flow stress. This phenomenon retards the fatigue crack growth rate regardless of the slip localization at a crack tip. Moreover, with decreasing test frequency, $f$, the fatigue crack growth rate increases but gradually approaches an upper limit of growth rate acceleration. The existence of this upper limit can be explained as the result of competition between the hydrogen diffusion rate and the dislocation velocity, which, depending on the strain rate, determines the trapping of hydrogen atoms at a dislocation core. All these conclusions are supported by microscopic observation, made by using the replica method, and by EBSD observations on the strain-induced martensitic transformation.

\section{ACKNOWLEDGMENTS}

The authors thank Professor P. Sofronis, University of Illinois, and Professor J. Solin, VTT Technical Research Centre of Finland (currently Kyushu University and HYDROGENIUS, AIST), for the useful discussion and comments on the interaction between hydrogen and dislocations. This research has been supported by the NEDO Fundamental Research Project on Advanced Hydrogen Science (2006 to 2012).

\section{OPEN ACCESS}

This article is distributed under the terms of the Creative Commons Attribution Noncommercial License which permits any noncommercial use, distribution, and reproduction in any medium, provided the original author(s) and source are credited.

\section{REFERENCES}

1. A.R. Troiano: Trans. Am. Soc. Met., 1960, vol. 52, pp. 54-80.

2. R.A. Oriani and P.H. Josephic: Acta Metall., 1974, vol. 22, pp. 1065-74.

3. C.D. Beachem: Metall. Trans., 1972, vol. 3, pp. 437-51

4. S.P. Lynch: Acta Metall., 1988, vol. 36, pp. 2639-61.

5. H.K. Birnbaum and P. Sofronis: Mater. Sci. Eng. A, 1994, vol. 176A, pp. 191-202.

6. L. Zhong, R. Wu, A.J. Freeman, and G.B. Olson: Phys. Rev. B, 2000, vol. 62, pp. 13938-13941.

7. G. Lu and E. Kaxiras: Phys. Rev. Lett., 2005, vol. 94, pp. 1555011-155501-4.

8. R.M. Vennet and G.S. Ansell: Trans. Am. Soc. Met., 1967, vol. 60, pp. $242-51$.

9. M.R. Louthan, Jr., G.R. Caskey, J.A. Donovan, and D.E. Rawl, Jr.: Mater. Sci. Eng., 1972, vol. 10, pp. 357-68.

10. H. Cialone and R.J. Asaro: Metall. Trans. A, 1979, vol. 10A, pp. 367-75.

11. R.E. Stoltz and A.J. West: in Hydrogen Effects in Metals, I.M. Bernstein and A.W. Thompson, eds., AIME, Warrendale, PA, 1981, pp. 541-53.

12. S.L. Robinson and N.R. Moody: J. Nucl. Mater., 1986, vol. 140, pp. 245-51.

13. M.-J. Lii, X.-F. Chen, Y. Katz, and W.W. Gerberich: Acta Metall. Mater., 1990, vol. 38, pp. 2435-53.

14. J. Toplosky and R.O. Ritchie: Scripta Metall., 1981, vol. 15, pp. $905-08$.

15. T.B. McLaren and A.W. Thompson: Mater. Sci. Eng., 1983, vol. 57, pp. L21-L25.

16. G. Schuster and C. Altstetter: Metall. Trans. A, 1983, vol. 14A, pp. 2085-90.

17. M. Itatani, Y. Miyoshi, and K. Ogura: Eng. Fract. Mech., 1988, vol. 30 , pp. $337-48$

18. Y. Murakami: Int. J. Fract., 2006, vol. 138, pp. 167-95.

19. H. Tanaka, N. Homma, S. Matsuoka, and Y. Murakami: Trans. Jpn. Soc. Mech. Eng. A, 2007, vol. 73, pp. 1358-65 (in Japanese).

20. Y. Murakami, T. Kanezaki, Y. Fukushima, H. Tanaka, J. Tomuro, K. Kuboyama, M. Matsue, Y. Ito, and H. Ando: Trans. Jpn. Soc. Mech. Eng. A, 2009, vol. 75, pp. 93-102 (in Japanese).

21. M.R. Louthan, Jr.: Scripta Metall., 1983, vol. 17, pp. 451-54.

22. T. Tabata and H.K. Birnbaum: Scripta Metall., 1984, vol. 18, pp. 231-36.

23. I.M. Robertson and H.K. Birnbaum: Acta Metall., 1986, vol. 34, pp. 353-66.

24. P. Rozenak, I.M. Robertson, and H.K. Birnbaum: Acta Metall. Mater., 1990, vol. 38, pp. 2031-40.

25. C.W. Tien and C.J. Altstetter: Mater. Chem. Phys., 1993, vol. 35, pp. $58-63$.

26. H.K. Birnbaum: Scripta Metall. Mater., 1994, vol. 31, pp. 149-53.

27. D.G. Ulmer and C.J. Altstetter: Acta Metall. Mater., 1991, vol. 39, pp. $1237-48$.

28. D.P. Abraham and C.J. Altstetter: Metall. Mater. Trans. A, 1995, vol. 26A, pp. 2859-71.

29. K.A. Nibur, D.F. Bahr, and B.P. Somerday: Acta Mater., 2006, vol. 54, pp. 2677-84.

30. D. Eliezer, D.G. Chakrapani, C.J. Altstetter, and E.N. Pugh: Metall. Trans. A, 1979, vol. 10A, pp. 935-41.

31. A. Inoue, Y. Hosoya, and T. Masumoto: Trans. Iron Steel Inst. Jpn., 1979, vol. 19, pp. 170-78. 
32. G. Han, J. He, S. Fukuyama, and K. Yokogawa: Acta Mater., 1998, vol. 46, pp. 4559-70.

33. S. Asano and R. Otsuka: Scripta Metall., 1976, vol. 10, pp. 1015-20.

34. D.P. Abraham and C.J. Altstetter: Metall. Mater. Trans. A, 1995, vol. 26A, pp. 2849-58.

35. C. San Marchi, B.P. Somerday, X. Tang, and G.H. Schiroky: Int. J. Hydrogen Energy, 2008, vol. 33, pp. 889-904.

36. M. Maxelon, A. Pundt, W. Pyckhout-Hintzen, and R. Kirchheim: Scripta Mater., 2001, vol. 49, pp. 817-22.

37. R. Kirchheim: Acta Mater., 2007, vol. 55, pp. 5139-48.

38. V.G. Gavriljuk, V.N. Shivanyuk, and J. Foct: Acta Mater., 2003, vol. 51, pp. 1293-1305.

39. V.G. Gavriljuk, V.N. Shivanyuk, and B.D. Shanina: Acta Mater., 2005, vol. 53, pp. 5017-24.

40. H. Matsui, H. Kimura, and S. Moriya: Mater. Sci. Eng., 1979, vol. 40 , pp. 207-16.

41. S. Moriya, H. Matsui, and H. Kimura: Mater. Sci. Eng., 1979, vol. 40, pp. 217-25.

42. Y. Murakami: Metal Fatigue: Effects of Small Defects and Nonmetallic Inclusions, Oxford, United Kingdom, Elsevier, 2002.

43. H. Uyama, M. Nakashima, K. Morishige, Y. Mine, and Y. Murakami: Fatigue Fract. Eng. Mater. Struct., 2006, vol. 29, pp. 1066-74.

44. Y. Murakami, T. Kanezaki, Y. Mine, and S. Matsuoka: Metall. Mater. Trans. A, 2008, vol. 39A, pp. 1327-39.
45. T. Kanezaki, C. Narazaki, Y. Mine, S. Matsuoka, and Y. Murakami: Int. J. Hydrogen Energy, 2008, vol. 33, pp. 2604-19.

46. C. San Marchi, B.P. Somerday, and S.L. Robinson: Int. J. Hydrogen Energy, 2007, vol. 32, pp. 100-16.

47. T. Kimoto, Y. Mine, S. Matsuoka, and Y. Murakami: Kyushu University, Fukuoka, Japan, unpublished research, 2008.

48. J.P. Chateau, D. Delafosse, and T. Magnin: Acta Mater., 2002, vol. 50 , pp. $1507-22$.

49. W.A. McInteer, A.W. Thompson, and I.M. Bernstein: Acta Metall., 1980, vol. 28, pp. 887-94.

50. X. Tang and A.W. Thompson: Mater. Sci. Eng. A, 1994, vol. A186, pp. 113-19.

51. P. Sofronis: J. Mech. Phys. Solids, 1995, vol. 43, pp. 1385-1407.

52. P. Sofronis and H.K. Birnbaum: J. Mech. Phys. Solids, 1995, vol. 43, pp. 49-90.

53. E. Sirois and H.K. Birnbaum: Acta Metall. Mater., 1992, vol. 40, pp. $1377-85$.

54. Y. Yamaguchi, Y. Mine, and Y. Murakami: Kyushu University, Fukuoka, Japan, unpublished research, 2009.

55. K. Kakimoto: Kyushu University, Fukuoka, Japan, unpublished research, 2008.

56. S. Taketomi, R. Matsumoto, and N. Miyazaki: J. Mater. Sci., 2008, vol. 43, pp. 1166-69.

57. S. Matsuoka, N. Tsutsumi, and Y. Murakami: Trans. Jpn. Soc. Mech. Eng. A, 2008, vol. 74, pp. 1528-37. 